\title{
HEMOPHILIA. I. THE ABNORMAL COAGULATION OF THE BLOOD AND ITS RELATION TO THE BLOOD PLATELETS
}

\author{
BY ARTHUR J. PATEK, JR., AND RICHARD P. STETSON \\ (From the Thorndike Memorial Laboratory, Second and Fourth Medical Services (Harvard), \\ Boston City Hospital, and the Department of Medicine, Harvard Medical School, Boston)
}

(Received for publication June 23, 1936)

The one abnormality constantly found in hemophilia is an inability of the blood to coagulate in a normal manner. This defect is demonstrable usually by a prolonged clotting time, which in turn determines the various manifestations of the disease. Further understanding of this disease depends, therefore, upon knowledge of the cause of the prolonged clotting time. Most investigations of the blood clotting mechanism in hemophilia have been made with methods involving the recalcification of oxalated or citrated plasma, and have been interpreted in terms of the several theories of blood coagulation. In the present study this approach to the problem has been abandoned for two reasons: (1) the recalcification of plasma is an artificial, indirect procedure which may not reflect physiological changes; (2) the theories of blood coagulation, with their varied nomenclature, possibly have served to confound rather than to clarify understanding of this disease.

The present study is based upon the well recognized observation that transfusion with normal blood reduces the clotting time of whole blood in hemophilia. It was assumed, therefore, that normal blood contains a substance which either supplies a clotting factor lacking from hemophilic blood or which counteracts a mechanism inhibiting coagulation of the blood in hemophilia. The analysis of the nature of this substance or substances contained in normal blood has been the aim of these observations. Since such inquiry has been made by many workers, certain of the observations recorded here are repetitious of other studies in this field. However, these differed in methods, concepts, or interpretations from the present work. A critical evaluation of the views of other investigators will be reserved for later discussion.

\section{METHODS}

Normal blood was obtained by venipuncture and was mixed gently with such an amount of 2.5 per cent sodium citrate in distilled water that the final concentration was 0.25 per cent. Conditions for the observation of clotting times were kept rigidly uniform. Acid-cleaned test tubes $100 \times 12 \mathrm{~mm}$. were used. The test blood or blood constituent was pipetted to the bottom of the tube, which had been freshly rinsed with 0.85 per cent solution of sodium chloride. Hemophilic blood was then obtained by venipuncture, the needle of the syringe removed, and exactly $2 \mathrm{cc}$. added to the tube containing the test material-discarding, however, the last three or four cubic centimeters of blood in the syringe. Control clotting times were made by adding hemophilic blood to tubes containing normal saline in amounts similar to the test material. The adding of hemophilic blood in this manner provided adequate mixing. Shaking the tubes was avoided, since such agitation provoked irregular responses. The tubes were then immersed directly in a water bath at $37^{\circ} \mathrm{C}$. After five minutes and at intervals thereafter, they were examined by gently tilting in order to see if the surface had jelled sufficiently to sustain the blood when the tube was inverted. The time after venipuncture at which this occurred was read as the clotting time. With such precautions a remarkably close check was obtained with duplicate observations, which invariably were made.

Except when otherwise stated, this procedure was followed in the experiments to be described, and henceforth will be referred to as "standard technique." It is essential, in making comparative readings on clotting time to have uniformity in the size of the tubes, in the amount of blood, and in the temperature. It is essential also that the syringe be clean and well rinsed with saline, and that the venipuncture be directly successful. Admixture with tissue juice, as in puncture by "second intention," may give falsely reduced clotting times. We believe that in such studies it is desirable to make observations on patients with decidedly protracted clotting time, so that any reduction in time may be considerable. A clotting time of one to two hours at $37^{\circ} \mathrm{C}$. may be the equivalent of 5 to 10 hours at room temperature, and whereas duplicate tests done at room temperature may be widely variant, those done at $37^{\circ} \mathrm{C}$. agree within a few minutes of one another. For the sake of brevity and simplicity, only a few characteristic observations out of many are reported in this paper. 


\section{Studies with whole blood}

Effect on clotting time of hemophilic blood of adding citrated normal blood in vitro. When varying amounts of citrated normal blood were added to $2 \mathrm{cc}$. of fresh hemophilic blood, it was found that as little as 0.05 cc. of normal blood, or a dilution of $1: 40$, was optimally effective in reducing the clotting time of the hemophilic blood (Table I). Therefore greater dilution was tried

TABLE I

Observations on clotting time after adding citrated normal blood to $2 \mathrm{cc}$. of hemophilic blood in standard tubes

$(100 \times 12 \mathrm{~mm}$.

\begin{tabular}{c|c|c|c}
\hline \multirow{2}{*}{$\begin{array}{c}\text { Citrated } \\
\text { normal blood }\end{array}$} & \multicolumn{3}{|c}{ Clotting times } \\
\cline { 2 - 4 } & Case I & Case II & Case III \\
\hline$c c$. & minutes & minutes & minutes \\
0.0 & 28 & 90 & 29 \\
0.05 & 7 & 7 & 9 \\
0.1 & 6 & 7 & 9 \\
0.2 & 7 & 6 & 9 \\
\hline
\end{tabular}

by adding like amounts of normal blood to $4 \mathrm{cc}$. of hemophilic blood. For this purpose, larger tubes, $110 \times 14 \mathrm{~mm}$. were necessary in place of the usual standard tubes. Here, too, the smallest amount of normal blood added was optimally effective in reducing the clotting time of hemophilic blood, even though the ratio of volumes between normal and hemophilic blood was 1:200 (Table II).

TABLE II

Observations on clotting time after adding citrated normal blood to $4 \mathrm{cc}$. of hemophilic blood in larger tubes $(110 \times 14 \mathrm{~mm}$. $)$

\begin{tabular}{c|c|c|c}
\hline \hline \multirow{2}{*}{$\begin{array}{c}\text { Citrated } \\
\text { normal blood }\end{array}$} & \multicolumn{3}{|c}{ Clotting times } \\
\cline { 2 - 4 } & Case I & Case II & Case III \\
\hline cc. & minutes & minutes & minutes \\
0.0 & 170 & 60 & 90 \\
0.02 & 20 & 23 & 27 \\
0.05 & 15 & 23 & 16 \\
0.1 & 15 & 30 & 22 \\
\hline
\end{tabular}

The effect on the clotting time of normal blood of adding citrated hemophilic blood in vitro. In each of several standard tubes were pipetted graded amounts of citrated hemophilic blood. Thereupon 2 cc. of normal blood were added to each tube. However, the clotting time of the normal blood remained unchanged (Table III).
TABLE III

Observations on clotting time after adding graded amounts of citrated hemophilic blood to $2 \mathrm{cc}$. of normal blood *

\begin{tabular}{|c|c|}
\hline & $\underset{\text { time }}{\text { Clotting }}$ \\
\hline $\begin{array}{l}2 \text { cc. normal blood } \ldots \ldots .03 \text { cc. hemophilic blood } \ldots \\
2 \text { cc. normal blood }+0.0 \\
2 \text { cc. normal blood }+0.05 \text { cc. hemophilic blood } \ldots\end{array}$ & $\begin{array}{c}\text { minutes } \\
11 \\
12 \\
11\end{array}$ \\
\hline
\end{tabular}

* Hemophilic blood had clotting time of 2 hours.

Effect of adding citrated hemophilic blood to another hemophilic blood in vitro. In each of several standard tubes were pipetted $(a)$ graded amounts of citrated hemophilic blood whose clotting time was 35 minutes, and $(b)$ in another series of tubes were pipetted similar amounts of citrated hemophilic blood with a clotting time of 105 minutes. To each of the tubes was then added $2 \mathrm{cc}$. of the control or test hemophilic blood whose clotting time was 25 minutes. No significant change in the latter's clotting time occurred (Table IV).

TABLE IV

Observations on clotting time of hemophilic blood after adding graded amounts of another hemophilic blood *

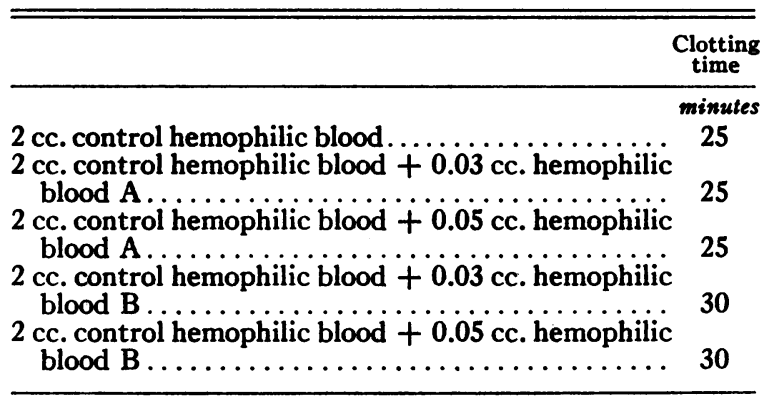

* Hemophilic blood A had clotting time of 35 minutes. Hemophilic blood B had clotting time of 105 minutes.

Effect of transfusion with normal citrated blood on the clotting time of hemophilic blood. Normal blood, when transfused into patients with hemophilia, abruptly reduced the clotting time. This occurred with amounts as small as $30 \mathrm{cc}$. and the effect could be detected five to ten minutes after transfusion. As in the test tube, whether this normal blood represented to the patient's calculated blood volume a ratio of $1: 8$ or $1: 53$, an approximately equivalent reduction in clotting time was observed. The smaller amounts, however, provided usually a more transient effect than the larger amounts. The clotting time gradually 


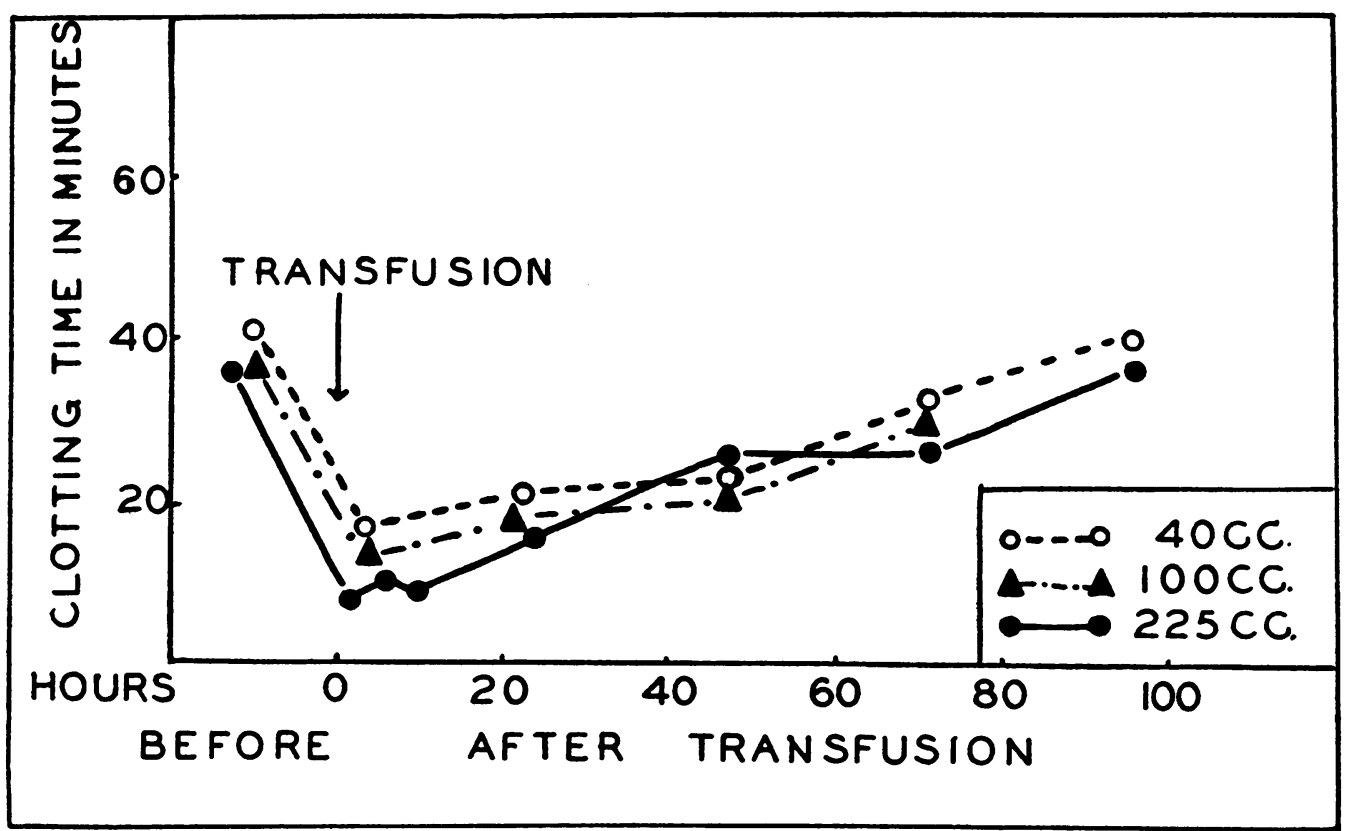

Figure 1. Observations on the Clotting Time of Hemophilic Blood after Transfusion with Varying Amounts of Citrated Normal Blood (Case I).

increased, in most instances reaching and surpassing the initial level in three to four days. Normal citrated blood kept three days at ice-box temperature (5 to $10^{\circ} \mathrm{C}$.) was equally effective (Figures 1 and 2).

There is a substance in normal blood which in small quantity effectively reduces the clotting time of hemophilic blood, both in vitro and in vivo. This substance is stable at ice-box temperature. Since the addition of hemophilic blood to normal blood does not prolong the clotting time of normal blood, it appears that the defective coagulation in hemophilia is not due to an inhibitory agent. Since the addition of one hemophilic blood to another did not alter the clotting of the control or test blood, it may be assumed that the previous changes observed on the addition of normal blood were specific and were not due to the mechanical admixture of two blood samples.

\section{Studies with blood components}

Comparison of blood, plasma, and serum in vitro. Comparison was made of equivalent amounts of citrated normal blood, plasma, and serum in their clot-accelerating action on hemophilic blood. Normal blood was obtained by venipuncture. One portion of this was citrated by standard technique. A second portion was citrated, then centrifuged immediately at 1,500 r.p.m. for 20 minutes, and the plasma removed. A third uncitrated portion was allowed to clot at room temperature, then centrifuged immediately at 1,500 r.p.m. for 20 minutes, and the serum removed. Manipulation was done by sterile technique. Tests were made at varying intervals of time of the relative potency of these portions in reducing the clotting time of hemophilic blood. When not in use, the blood, plasma, and serum were kept at ice-box temperature. Tests were made by pipetting $0.1 \mathrm{cc}$. of citrated normal blood, $0.05 \mathrm{cc}$. of plasma or of serum to the bottom of standard tubes. To each of these were added 2 cc. of fresh hemophilic blood. It is evident from the data given in Table $\mathrm{V}$ that whole blood was the most effective in reducing the clotting time of hemophilic blood, that plasma was slightly less so, and that serum, although somewhat active when fresh, lost its potency after several days.

Effect of transfusion with normal serum on the clotting time of hemophilic blood. The intravenous injection of serum was done twice. In one case the normal blood was allowed to clot at room temperature, and after removal and Berkefeld filtration, the serum was kept at ice-box tem- 


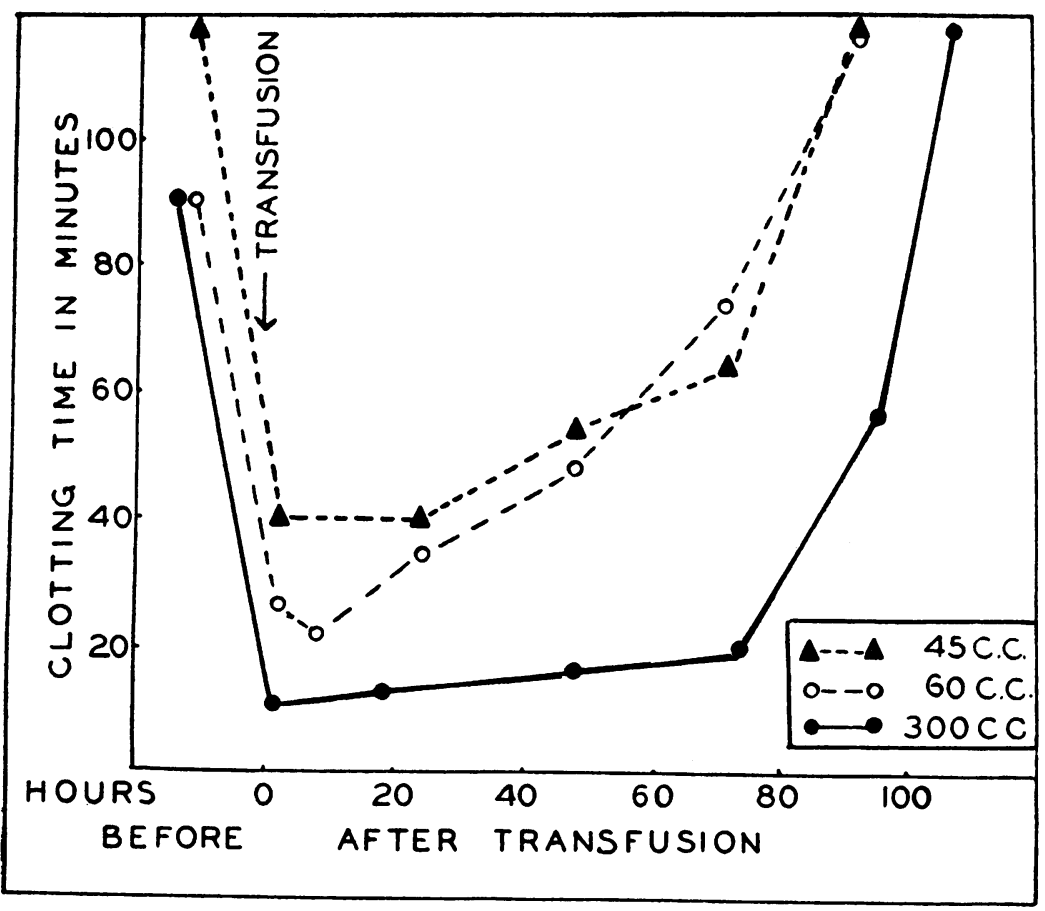

Figure 2. Observations on the Clotting Time of Hemophilic Blood after Transfusion with Varying Amounts of Citrated Normal Blood (CASE II).

TABLE $\mathbf{V}$

Observations on clotting time of hemophilic blood after adding citrated normal blood, plasma, and serum in equivalent amounts at varying intervals of time

\begin{tabular}{|c|c|c|c|c|c|}
\hline \multirow{2}{*}{$\begin{array}{c}\text { Case } \\
\text { number }\end{array}$} & \multicolumn{4}{|c|}{ Clotting time } & \multirow{2}{*}{$\begin{array}{c}\text { Age of test } \\
\text { material }\end{array}$} \\
\hline & $\begin{array}{c}\text { Control } \\
\text { hemophilic } \\
\text { blood }\end{array}$ & $\begin{array}{l}0.1 \text { cc. } \\
\text { blood }\end{array}$ & $\begin{array}{l}0.05 \mathrm{cc} . \\
\text { plasma }\end{array}$ & $\begin{array}{l}0.05 \text { cc. } \\
\text { serum }\end{array}$ & \\
\hline I & $\begin{array}{c}\text { minutes } \\
105 \\
105 \\
100 \\
60\end{array}$ & $\begin{array}{c}\text { minutes } \\
14 \\
12 \\
15 \\
25\end{array}$ & $\begin{array}{c}\text { minutes } \\
26 \\
14 \\
26 \\
28\end{array}$ & $\begin{array}{c}\text { minutes } \\
32 \\
35 \\
38 \\
80\end{array}$ & $\begin{array}{r}2 \text { hours } \\
4 \text { days } \\
8 \text { days } \\
11 \text { days }\end{array}$ \\
\hline II & $\begin{array}{l}150 \\
150 \\
130 \\
130+\end{array}$ & $\begin{array}{l}14 \\
20 \\
11 \\
15\end{array}$ & $\begin{array}{l}26 \\
25 \\
12 \\
27\end{array}$ & $\begin{array}{c}32 \\
55 \\
60 \\
130+\end{array}$ & $\begin{array}{l}2 \text { hours } \\
2 \text { days } \\
4 \text { days } \\
8 \text { days }\end{array}$ \\
\hline
\end{tabular}

perature for four days. Intravenous injection of this serum to a patient with hemophilia was followed by no reduction of clotting time. In a second case a similar procedure was performed with normal serum which had formed at ice-box temperature and had remained in contact with the clot for two days. After Berkefeld filtration, this serum was injected intravenously on the third day. No change in clotting time of hemophilic blood occurred (Table VI). In vitro studies made with these sera according to standard technique were likewise negative.

TABLE VI

Observations on clotting time of hemophilic blood after transfusion with aged normal serum

\begin{tabular}{|c|c|c|}
\hline & \multicolumn{2}{|c|}{ Clotting time } \\
\hline & $A^{*}$ & $\mathrm{~B}^{*}$ \\
\hline $\begin{array}{l}\text { Before injection } \ldots \ldots \ldots \ldots \ldots \ldots \ldots \ldots \\
2 \text { hours after injection } . \ldots \ldots \ldots \ldots \ldots \ldots \\
\mathbf{4} \text { hours after injection } \ldots \ldots \ldots \ldots \ldots \ldots \ldots \\
8 \text { hours after injection } \ldots \ldots \ldots \ldots \ldots \ldots\end{array}$ & $\begin{array}{c}\text { minutes } \\
30 \\
33 \\
35\end{array}$ & $\begin{array}{c}\text { minutes } \\
180 \\
180 \\
120 \\
120\end{array}$ \\
\hline
\end{tabular}

* (A) 100 cc. serum 3 days old. (B) 35 cc. serum 4 days old.

These findings are in contrast to the action of fresh serum injected intravenously, as noted also by Addis (6a) and likewise in contrast to our in vitro studies with fresh serum, which had the ability to hasten clotting of hemophilic blood.

Thus, whereas this clot-accelerating factor was stable in both blood and plasma, the serum effect was peculiarly labile. Attention, therefore, was 
directed to the plasma and its constituents, since preliminary studies indicated that its activity more closely paralleled that of whole blood.

In vitro studies with plasma subjected to filtration and protracted centrifugation. Fresh normal blood, obtained by venipuncture, was placed directly in paraffin-lined centrifuge tubes containing sodium citrate. Plasma was removed by standard technique, with the exception that all materials used in the manipulation were paraffin-coated. A portion of the plasma was kept whole, and a second portion was filtered through six thicknesses of number 42 filter paper. Of these portions onehalf was centrifuged at 3,000 r.p.m. for $45 \mathrm{~min}$ utes, and the top layer used for testing. In contrast to whole plasma, centrifuged whole and filtered plasmas contained by microscopic observation very few platelets. The relative effectiveness of these plasmas was then tested by standard technique against hemophilic blood.

Filtration and centrifugation resulted in little, if any, loss of potency (Table VII). The addi-

\section{TABLE VII}

Observations on clotting time of hemophilic blood after adding normal platelet-poor plasma, as obtained by filtration or centrifugation

\begin{tabular}{|c|c|c|}
\hline & \multicolumn{2}{|c|}{ Clotting time } \\
\hline & Case I & Case II \\
\hline \multirow{7}{*}{ 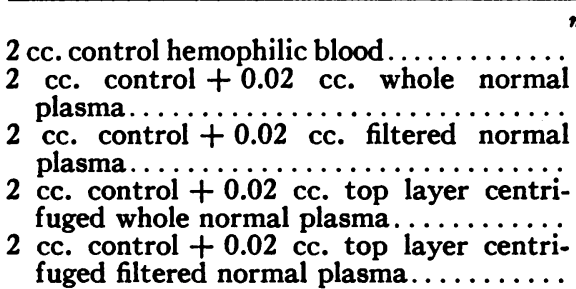 } & minutes & minutes \\
\hline & 55 & 120 \\
\hline & & 25 \\
\hline & & \\
\hline & 20 & 30 \\
\hline & 20 & 30 \\
\hline & 20 & 35 \\
\hline
\end{tabular}

tion of either plasma caused prompt reduction in the clotting time of hemophilic blood. Similar observations were made with oxalated plasma, and the results obtained were essentially the same. Whereas the dilution of these plasmas in hemophilic blood (.02 in 2 cc.) was about $1: 100$, similar observations were made with equal volumes of plasma which had been diluted with saline in order to make a relative dilution of 1:200 and of $1: 300$. There was a tendency towards slight reduction of clot-promoting power of these plasmas with higher dilutions.

In vitro studies with plasma of purpura blood.
Fresh citrated plasma was obtained from normal subjects and was compared to that obtained from patients with thrombopenic purpura. These patients characteristically revealed prolonged bleeding time, and their blood showed extreme thrombopenia and non-retractile clot. Their plasma was used because, without being subjected to manipulation, it contained very few platelets. One case was due to arsphenamine therapy; one was associated with a late phase of aplastic anemia; two were instances of idiopathic thrombopenic purpura. Tests were made by standard technique of the relative effectiveness of such platelet-poor plasmas as compared to that of normal subjects. No demonstrable differences were found in the behavior of the plasmas from the various types of purpura, which were as effective as normal plasma in reducing the clotting time of hemophilic blood. An example of the potency of the respective plasmas is illustrated by Table VIII.

TABLE VIII

Observations on clotting time of hemophilic blood after adding citrated plasma of normal subject and of patient with thrombopenic purpura

\begin{tabular}{l|c|c|c|c}
\hline & \multicolumn{4}{|c}{ Clotting time } \\
\cline { 2 - 5 } Plasma & \multicolumn{2}{|c}{ Normal plasma } & \multicolumn{2}{c}{ Purpura plasma } \\
\cline { 2 - 5 } & Case I & Case II & Case I & Case II \\
\cline { 2 - 5 } & minutes & minutes & minutes & minutes \\
\hline$c c$. & 30 & 120 & 30 & 120 \\
0.0 & 6 & 25 & 8 & 28 \\
0.02 & 5 & 15 & 7 & 18 \\
0.05 & 5 & 18 & 6 & 11 \\
\hline
\end{tabular}

In vitro studies with normal plasma passed through the Berkefeld filter. Fresh citrated normal plasma was obtained by standard technique. One portion was kept as such; another was passed through a Berkefeld filter. ${ }^{1}$ The latter was entirely free from cellular constituents. Standard tests were made with like amounts of the plasmas so prepared, after being stored at $8^{\circ} \mathrm{C}$. for four days and thirty days. Both retained activity. It was observed that the clot-accelerating action of whole normal plasma was not affected significantly by filtration (Table IX).

\footnotetext{
1 Hereafter in this paper the term "filtered" will denote passage through the Berkefeld filter (Grade V) unless otherwise specified.
} 
TABLE IX

Observations on clotting time of hemophilic blood after adding normal citrated plasma, whole or filtered

\begin{tabular}{|c|c|c|c|c|}
\hline \multirow{3}{*}{ Plasma } & \multicolumn{4}{|c|}{ Clotting time } \\
\hline & \multicolumn{2}{|c|}{$\begin{array}{l}\text { Whole normal plasma, } \\
4 \text { days old }\end{array}$} & \multicolumn{2}{|c|}{$\begin{array}{l}\text { Filtered normal plasma, } \\
4 \text { days old }\end{array}$} \\
\hline & Case I & Case II & Case I & Case II \\
\hline \multirow[t]{2}{*}{$\begin{array}{l}\text { cc. } \\
0 \\
0.02 \\
0.05 \\
0.1 \\
0.3\end{array}$} & $\begin{array}{c}\text { minutes } \\
32 \\
15 \\
13 \\
11 \\
11\end{array}$ & $\begin{array}{c}\text { minutes } \\
90 \\
36 \\
36 \\
30 \\
30\end{array}$ & $\begin{array}{c}\text { minutes } \\
32 \\
20 \\
17 \\
11 \\
11\end{array}$ & $\begin{array}{c}\text { minutes } \\
90 \\
40 \\
37 \\
30 \\
30\end{array}$ \\
\hline & \multicolumn{2}{|c|}{$\begin{array}{l}\text { Whole normal plasma, } \\
30 \text { days old }\end{array}$} & \multicolumn{2}{|c|}{$\begin{array}{c}\text { Filtered normal plasma, } \\
30 \text { days old }\end{array}$} \\
\hline $\begin{array}{l}0 \\
0.1\end{array}$ & & $\begin{array}{r}120 \\
30\end{array}$ & & $\begin{array}{r}120 \\
35\end{array}$ \\
\hline
\end{tabular}

In vitro comparison of normal and hemophilic plasmas. Whole and filtered plasma of citrated normal and hemophilic blood respectively were compared by standard technique in their clotpromoting power on another hemophilic blood. As observed previously, normal plasma, whether it was whole or filtered, reduced the clotting time of hemophilic blood, whereas this power was either absent from or greatly diminished in hemophilic plasma (Table X).

TABLE $X$

Observations on clotting time of hemophilic blood after adding normal and hemophilic plasma of another patient

\begin{tabular}{|c|c|c|}
\hline & \multicolumn{2}{|c|}{ Clotting time } \\
\hline & Case I & Case II \\
\hline \multirow{3}{*}{ 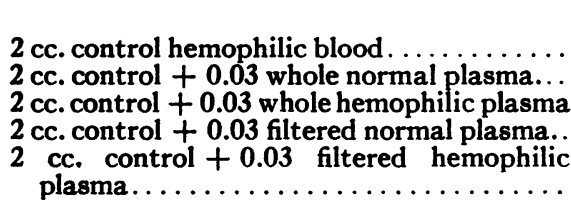 } & minutes & minutes \\
\hline & $\begin{array}{r}120 \\
28 \\
120 \\
-\quad 28\end{array}$ & $\begin{array}{l}75 \\
25 \\
75 \\
25\end{array}$ \\
\hline & 120 & 75 \\
\hline
\end{tabular}

The effect of transfusion with normal filtered plasma on the clotting time of hemophilic blood. Single intravenous injections of citrated filtered normal plasma reduced the clotting time of hemophilic blood for several hours. The plasma used was kept from three days to two months at icebox temperature. On one occasion this plasma was used to check hemorrhage. Transfusion with $150 \mathrm{cc}$. of such plasma, two months old, apparently stopped a protracted nosebleed in 10 minutes and reduced the clotting time from 2 hours to thirty minutes, 4 hours after the injection. A similar response was obtained by the intravenous injection of citrated plasma from a patient with thrombopenic purpura.

By giving daily intravenous injections of 75 to $100 \mathrm{cc}$. of filtered normal plasma for three days to a hemophilic patient, the clotting time was kept materially reduced during this time. The response with plasma was similar in pattern to but less durable than that of whole blood transfusion in these patients (Figures 3 and 4 ).

In normal plasma rendered free from platelets, whether by filtration or centrifugation, there is a substance which is effective in reducing the clotting time of hemophilic blood. This substance also resides in the plasma of thrombopenic purpura. It is stable at ice-box temperature and is potent in high dilution in vitro or in vivo. It is either unavailable or greatly diminished in hemophilic plasma.

\section{Study of the blood platelets in relation to the clotting of normal and hemophilic blood}

Since plasma, free from platelets, contained material effective in reducing the clotting time of hemophilic blood, several questions presented themselves: (1) was such plasma (filtered, for example) also free from platelet products; (2) did hemophilic platelets behave like normal platelets in their own plasma and in normal plasma; (3) did the addition of platelets or platelet material free from plasma influence the clotting time of hemophilic blood? Such inquiry was pertinent because some current theories hold that the hemophilic platelets, due to an abnormal stability, break up slowly and consequently liberate slowly a substance effective in clotting. The method for obtaining platelet material was as follows: $50 \mathrm{cc}$. of plasma was derived from citrated normal blood by standard technique. This was centrifuged at 1,500 r.p.m. for 20 minutes, the cloudy plasma removed, and then divided into two equal portions and recentrifuged at 2,000 r.p.m. for 2 hours. The white sediment at the bottom, which was composed of platelets, was washed twice with 0.85 per cent sodium chloride solution. One portion was resuspended 


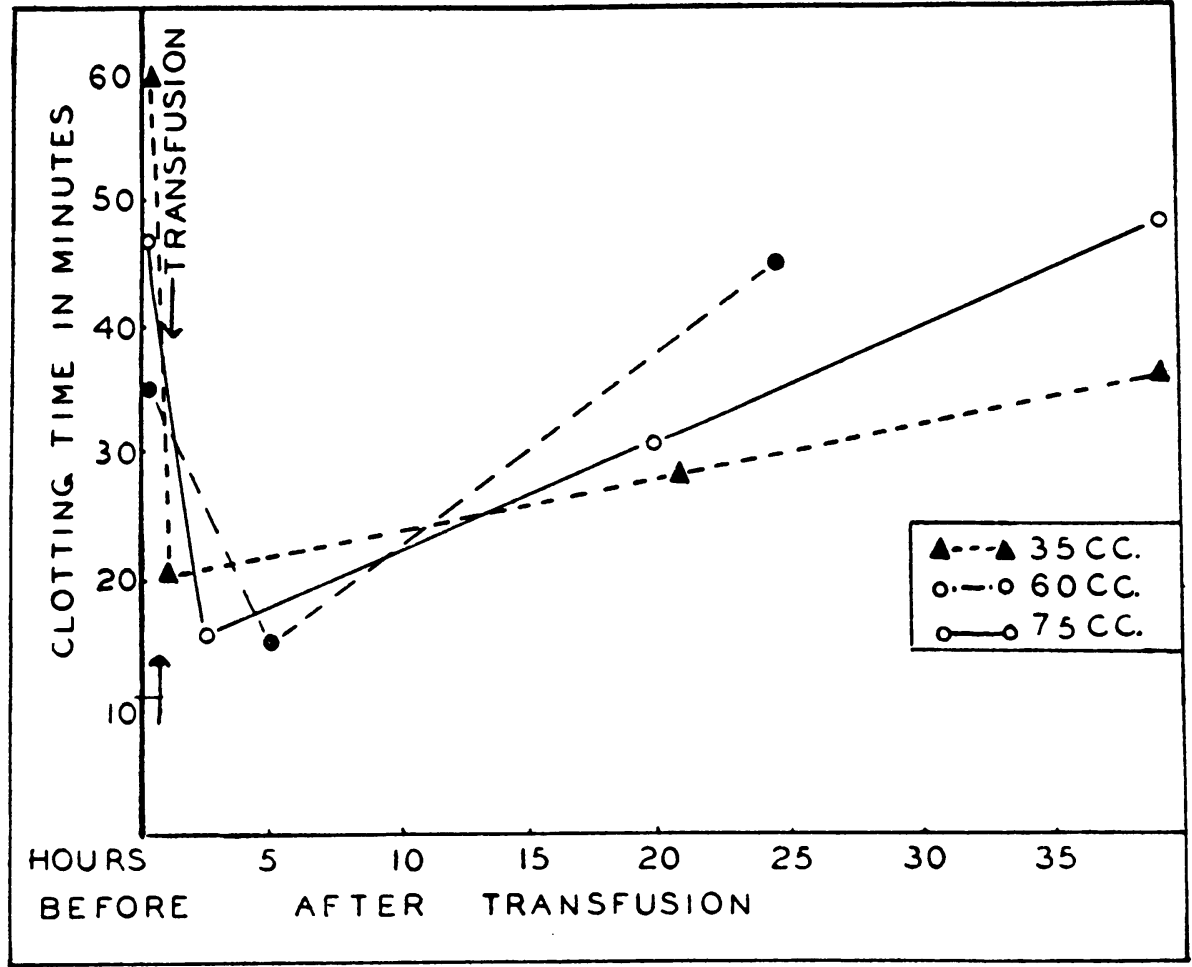

Figure 3. Observations on the Clotting Time of Hemophilic Blood after Single Transfusion with Filtered Normal Plasma (Case III).

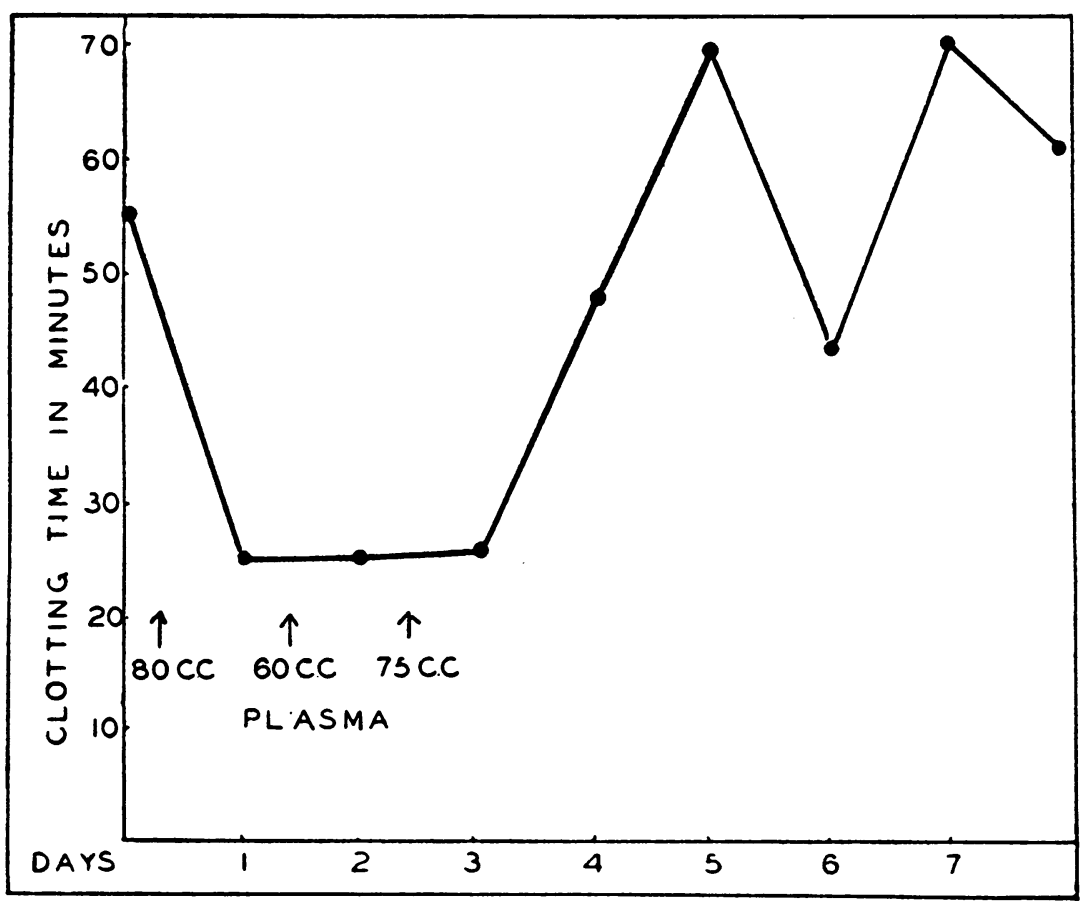

Figure 4. Observations on the Clotting Time of Hemophilic Blood after Multiple Transfusions with filtered normal Plasma (Case III). 
TABLE XI

Observations on clotting time of normal and hemophilic filtered plasma after the addition of normal and hemophilic platelet suspensions *

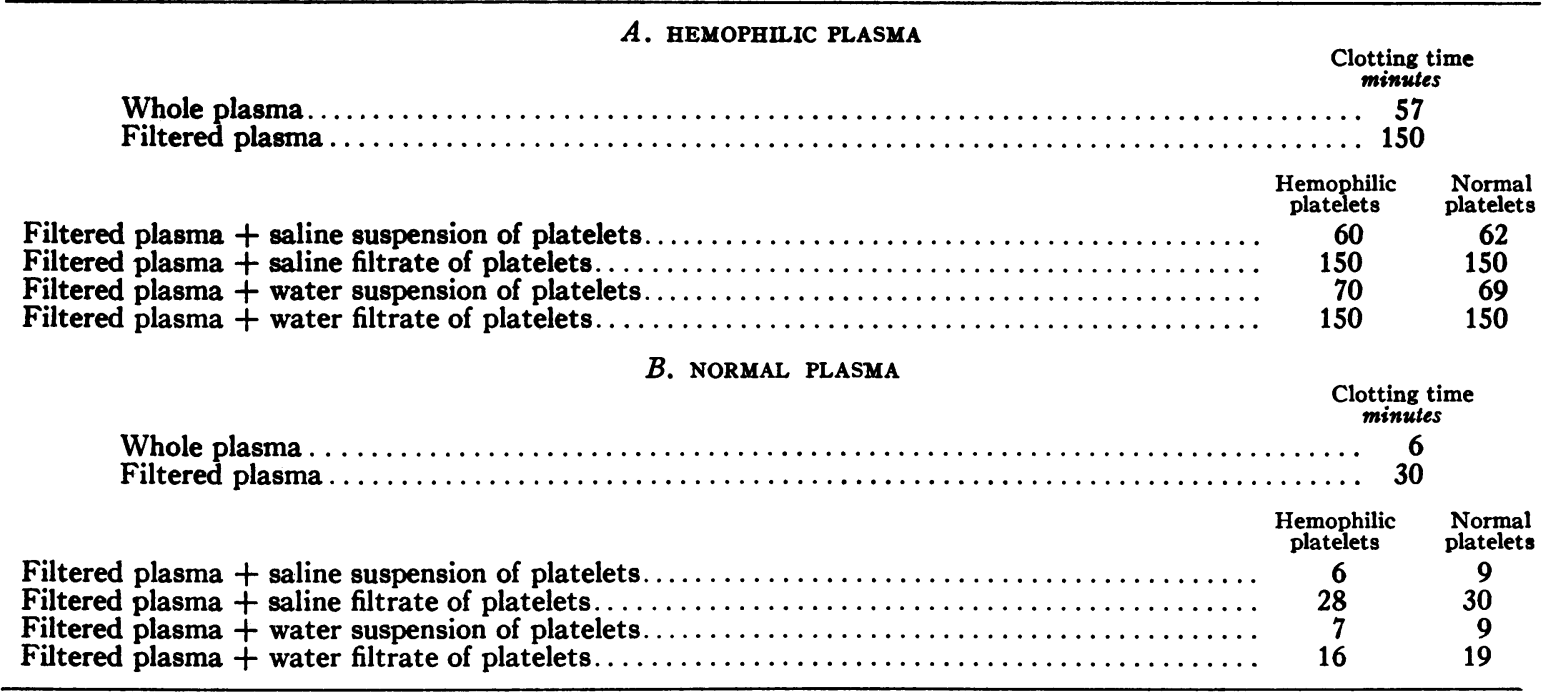

* To $0.2 \mathrm{cc}$. of each of the above plasmas were added successively $0.1 \mathrm{cc}$. of platelet suspension of physiological concentration and then $0.9 \mathrm{cc}$. of a "calcium solution." Each tube was shaken briefly to effect mixture and then immersed in a water bath at $37^{\circ} \mathrm{C}$.

in saline of the same volume as the plasma from which it was derived. The second portion was similarly resuspended in distilled water. After vigorous shaking to afford an even suspension of platelets each of these portions, in turn, was divided-part kept whole and part passed through the Berkefeld filter.

An exactly similar procedure was carried out with an equal volume of hemophilic plasma. Thus there resulted stoichiometric suspensions of normal and hemophilic platelets in water and in physiological saline, and of their respective filtrates.

Comparison of hemophilic and normal platelets in both hemophilic and normal plasmas. Comparison between the effects of plasma and of platelets from both hemophilic and normal blood was made by use of the method of recalcification of citrated plasma. This involved the addition to each tube successively of (1) $0.2 \mathrm{cc}$. of the test plasma; (2) $0.1 \mathrm{cc}$. of platelet suspension; and (3) $0.9 \mathrm{cc}$. of calcium solution. ${ }^{2}$ Then the tubes were shaken briefly and placed in the water bath at $37^{\circ} \mathrm{C}$.

2 Calcium solution was made up in lots composed of 80 cc. of 0.85 per cent $\mathrm{NaCl}+25$ cc. of 0.25 per cent $\mathrm{CaCl}_{2}$.
Observations are recorded in Table XI. The clotting of whole hemophilic plasma on recalcification required 57 minutes whereas the same plasma when filtered and recalcified required $150 \mathrm{~min}$ utes. Presumably this was due to loss of platelets. The addition of hemophilic or normal platelet suspensions to the filtered hemophilic plasma brought the clotting time back approximately to that of whole hemophilic plasma. A similar prolongation of clotting time occurred after Berkefeld filtration of normal plasma. Here, too, the addition of hemophilic or of normal platelet suspensions brought the clotting time back to that of whole normal plasma. Under the above conditions, hemophilic platelets provided the same accelerating effect as did normal platelets when added either to their own or to normal filtered plasma.

The platelet suspensions were then subjected to filtration. Their filtrates were added in a similar manner to filtered plasma from normal and from hemophilic blood. No accelerating effect was observed. Hence it was evident that filtration of platelets, however injured they were by water lysis and manipulation, allowed the transfer of virtually no clot-accelerating material into the filtrate. Therefore, it may be assumed 
that plasma, subjected to filtration, was also practically free from platelets and platelet products.

Comparison of normal and hemophilic plasma by method of recalcification. With the use of the technique described above, normal and hemophilic plasmas, whole and filtered, were tested for clotting time on recalcification. Again it was noted that Berkefeld filtration with removal of platelets, caused prolongation of both normal and hemophilic plasma clotting time. However, on adding $0.1 \mathrm{cc}$. of filtered normal plasma (clotting time 40 minutes) to $0.1 \mathrm{cc}$. of whole hemophilic plasma (clotting time 24 minutes) the resultant clotting time was but 8 minutes-that is, essentially normal. This demonstrated that platelet-free normal plasma, when added to whole

TABLE XII

Observations on clotting time of normal and hemophilic plasmas upon adding 0.9 cc. of "calcium solution"

\begin{tabular}{|c|c|}
\hline & $\begin{array}{c}\text { Clotting } \\
\text { time }\end{array}$ \\
\hline A & minutes \\
\hline $\begin{array}{l}0.2 \text { cc. whole normal plasma } \ldots \ldots \ldots \ldots \ldots \ldots \ldots \\
0.2 \text { cc. whole hemophilic plasma } \ldots \ldots \ldots \ldots \ldots \ldots \\
0.2 \text { cc. filtered normal plasma } \ldots \ldots \ldots \ldots \ldots \ldots \\
0.2 \text { cc. filtered hemophilic plasma } \ldots \ldots \ldots \ldots \ldots \ldots\end{array}$ & $\begin{array}{r}6 \\
24 \\
40 \\
210\end{array}$ \\
\hline
\end{tabular}

\section{B}

$0.1 \mathrm{cc}$. whole hemophilic plasma

0.1 cc. filtered normal plasma

0.1 cc. whole hemophilic plasma

0.1 cc. normal saline

0.1 cc. filtered normal plasma

0.1 cc. normal saline hemophilic plasma, supplied a material effective in producing normal clotting time on recalcification (Table XII).

In order to determine whether normal plasma acted directly on hemophilic plasma, or acted indirectly by activating the platelets, the following experiment was done: graded small amounts of filtered normal plasma were added to filtered hemophilic plasma, and the clotting times noted after recalcification. By this procedure the clotting time of filtered hemophilic plasma was reduced to that of filtered normal plasma (Table XIII). These results indicate that the effectiveness of normal plasma in reducing the clotting time of hemophilic blood does not necessarily depend upon activation of platelets.

Addition of platelet suspensions to hemophilic blood in vitro. Observations on the recalcification of citrated plasma suggested that platelets were not related to the defective coagulation in hemophilia. Such studies, however, involved an unphysiological procedure. That is to say, the recalcification of citrated plasma did not reflect necessarily the changes occurring in natural clotting. Therefore, platelet suspensions of the concentration in normal plasma, as prepared in the preceding study, were added directly to whole hemophilic blood by standard technique, and the clotting times noted. Although the platelet suspension was of physiological concentration, the number of normal platelets relative to the total volume of hemophilic blood was considerably less than physiological concentration. This amount was used simply for comparison with a like

TABLE XIII

Observations on clotting time of filtered hemophilic plasma after adding filtered normal plasma *

\begin{tabular}{|c|c|}
\hline & Clotting time \\
\hline 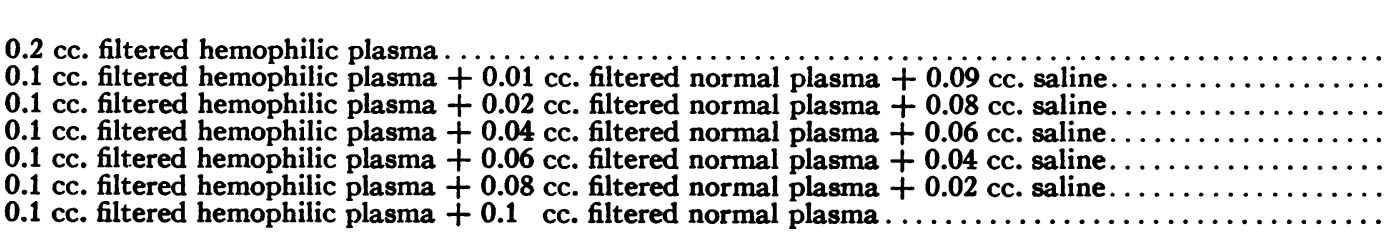 & $\begin{array}{r}\text { minutes } \\
270 \\
51 \\
53 \\
44 \\
39 \\
32 \\
30\end{array}$ \\
\hline
\end{tabular}

CONTROLS

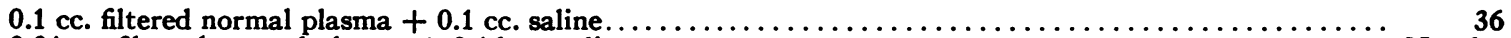

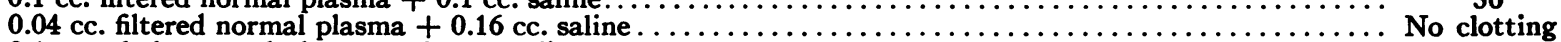

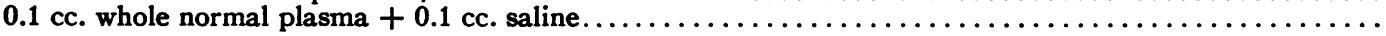

* To each tube was added 1 cc. of "calcium solution." The tubes were shaken briefly and then immersed in a water bath at $37^{\circ} \mathrm{C}$. 
TABLE XIV

Observations on clotting time of hemophilic blood after adding suspensions of normal and hemophilic platelets

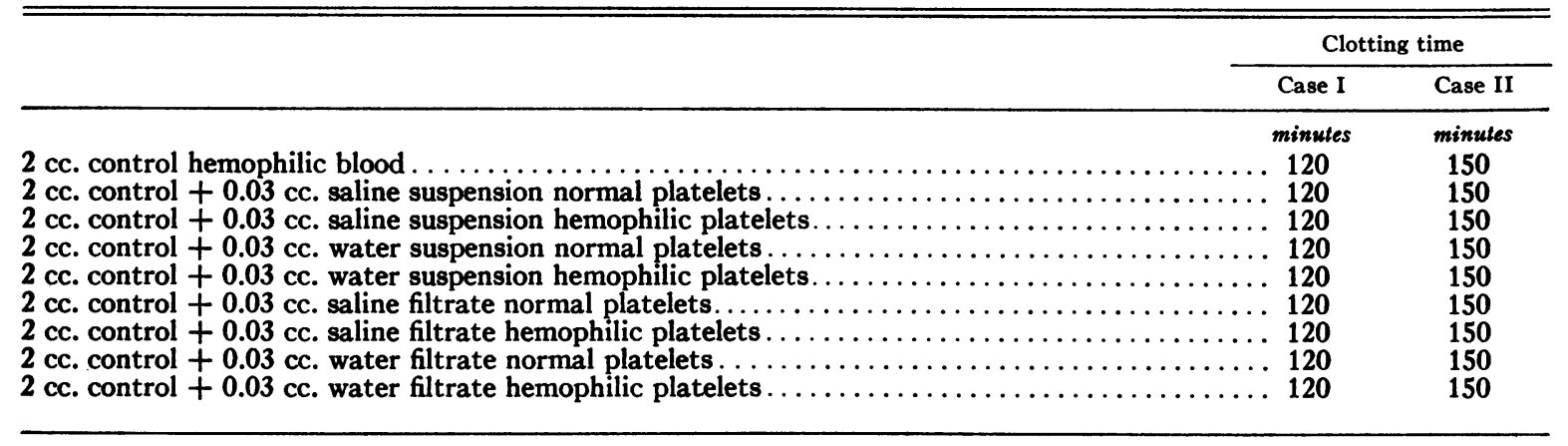

amount of platelet-free plasma, which had been shown to be optimally effective in reducing the clotting time of hemophilic blood. The addition of normal platelets in this concentration produced no change in the clotting time of the hemophilic blood (Table XIV).

In the clotting of either hemophilic or of normal plasma, hemophilic platelets behave similarly to normal platelets. Filtration prolongs the clotting time of both normal and of hemophilic plasmas on recalcification. This is due presumably to the removal of platelets. However, the addition of filtered normal plasma to whole hemophilic plasma causes a sharp reduction of clotting time on recalcification. This indicates that the clotpromoting substance provided by normal blood resides in the platelet-free plasma. Moreover, the addition of a suspension of normal platelets of the concentration present in normal plasma to whole hemophilic blood causes no change in the latter's clotting time.

\section{DISCUSSION}

It is not the purpose of this paper to review the mass of contradictory findings reported in the medical literature regarding the abnormality of blood coagulation in hemophilia. Convincing objections to the older theories of Wright (1), Sahli (2), Emile-Weil (3), Nolf and Herry (4) and Morawitz and Lossen (5) were presented in the excellent paper by Addis (6). A copious bibliography was also included in more recent articles by Minot and Lee (7), Hurwitz and Lucas (8) and Christie, Davies and Stewart (9). The latter authors, whose observations were interpreted in Howell's terminology, reported a long "prothrombin-time." This term, however, signified simply a long clotting time of hemophilic oxalated plasma on recalcification. In other words, it showed that plasma in hemophilia manifested the same clotting abnormality as that of the whole blood. Klinger (20) made similar observations. By exclusion of other factors it was assumed by these authors to represent a defect in the substance "prothrombin."

In our opinion only the studies of Addis (6) truly pointed with substantial reason to a defect in the plasma which was interpreted as a qualitative change in " prothrombin," a material closely allied chemically to fibrinogen, but whose exact chemical nature is obscure. Addis recorded a number of important observations : that hemophilic plasma added to normal plasma did not lengthen the latter's clotting time, and hence contained no inhibitory substance; that unlike plasma, the clotaccelerating action of serum was labile; that thromboplastic substances in strong concentration reduced the clotting time of both normal and hemophilic blood, whereas in weaker concentration they were capable of reducing only the clotting time of normal blood effectively. In the present study a similar inquiry was directed at the clotting abnormality of hemophilia by use of a more direct technique involving in vivo as well as in vitro studies, and it was ascertained that this defect in the plasma was independent of the formed elements of the blood.

The relationship of platelets to blood clotting has been of interest for many years. All observers agree that in shed blood, platelets play an important rôle in the inception of clotting. The removal of platelets, whether by centrifugation 
$(10,11)$ or by Berkefeld filtration $(12,13)$ and the consequent delay in clotting illustrates the point. Whether or not they are a source of "prothrombin" as well as "thromboplastin" is not of immediate concern.

In 1916 Minot and Lee (7) found that the addition of concentrated suspensions of normal platelets, unlike hemophilic platelets, caused a sharp reduction in the clotting time of hemophilic plasma on recalcification, whereas both normal and hemophilic platelet suspensions were essentially equal in their ability to hasten the clotting time of normal plasma. Fonio (14) and Wöhlisch (15) made similar observations. This was interpreted to mean that hemophilic platelets were only slowly available for purposes of enhancing coagulation. That these platelets behaved differently in normal plasma and in hemophilic plasma we interpret as indicating a difference of plasma rather than of platelets. It is possible that the normal platelets had not been adequately rinsed free of plasma. This could explain their greater effectiveness when added to hemophilic plasma. Studies by Feissly and Fried (19) clearly support this explanation. They demonstrated that although normal platelets appeared to be more effective than hemophilic platelets in hastening the clotting of hemophilic plasma, this difference did not exist after heating both platelet suspensions to $60^{\circ} \mathrm{C}$. The thromboplastic activity of platelets is relatively stable at this temperature, whereas the effective substance in platelet-free plasma, as will be described in a later communication, is thermolabile.

In 1926 Howell and Cekada (16) concluded that the earlier hypothesis by Howell (16a) of a reduction in the amount of prothrombin was wrong, and that their later studies indicated that " the prothrombin in hemophilic blood does not differ from that of normal blood either in its concentration or its properties." These authors noted that platelets of normal blood, after being shed, disintegrated and fused more rapidly than did platelets of hemophilic blood. From this it was inferred that hemophilic platelets are abnormally stable. In our opinion such an observation merely confirms the fact that clotting is slow, but it fails to reveal or to imply an abnormal stability of platelets.
Christie et al. (9) in 1927 noted that injury by lysis or by switching of hemophilic blood hastened its clotting. Birch (17) in 1932 and others have made similar observations, from which they concluded that the platelets were abnormally tough in hemophilia. Such an assumption does not appear justifiable. The mechanism of clotting is very complex, unstable, and easily disturbed by change in the physical environment. In the course of such manipulation surely many factors in the blood or plasma are altered, which conceivably could hasten clot production, and it is unsound to interpret the effects from trauma as due to a selective and simple lysis of platelets. Govaerts and Gratia (21) suggested in their preliminary study on one patient, that a plasma factor worked by activating the platelet, and that this factor was deficient in hemophilia. From the data presented in Table XIII this postulation does not seem tenable.

It is not implied that platelets are unimportant in coagulation, but it is inferred from our study that hemophilic platelets function as well as do normal platelets. One source of the confusion in the literature is the fact that most studies have been made with highly concentrated suspensions or emulsions of platelets. It is well known that concentrated suspensions of platelets, of thromboplastin, or cephalin hasten clotting of normal and hemophilic blood. Such an effect is not specific. However, when they were compared stoichiometrically-or in the concentration in which platelets normally exist in plasma-then, hemophilic platelets were shown to behave as do normal platelets, both in their own and in normal plasma. This finding has also been suggested by studies of Addis (6), Eagles (18) and Feissly and Fried (19).

More significant was our observation that the addition of such suspensions of platelets to hemophilic blood did not shorten its clotting time, whereas the addition of a minute quantity of platelet-free, normal plasma abruptly reduced the clotting time, indicating that the platelet was not involved in the clotting abnormality of hemophilia, and that the defect resided in the plasma. In vivo studies with filtered normal plasma supported this contention.

Further studies are being made towards the 
identification of this effective substance contained in normal plasma.

\section{CONCLUSIONS}

There is a substance present in normal plasma and markedly deficient or unavailable in hemophilic plasma which in small amounts effectively shortens the clotting time of hemophilic blood. This plasma substance is stable at ice-box temperature. It is independent of the formed elements of the blood.

For their ready cooperation, the authors are deeply indebted to four hemophilic patients : Russell White, Edward Woogmaster, James Smith, and Victor Marotta.

\section{BIBLIOGRAPHY}

1. Wright, A. E., On a method of determining the condition of blood coagulability for clinical and experimental purposes, and on the effect of the administration of calcium salts in haemophilia and actual or threatened haemorrhage. Brit. M. J., 1893, 2, 223.

2. Sahli, H., Weitere Beiträge zur Lehre von der Hämophilie. Deutsches Arch. f. klin. Med., 1910, 99, 518.

3. Emile-Weil, P., L'Hémophilie. Presse méd., 1905, 13, 673.

4. Nolf, P., and Herry, A., De L'Hémophilie. Pathogénie et traitement. Rev. de Méd., 1909, 29, 841.

5. Morawitz, P., and Lossen, J., Uber Hämophilie. Deutsches Arch. f. klin. Med., 1908, 94, 110.

6. Addis, T., The pathogenesis of hereditary haemophilia. J. Path. and Bact., 1911, 15, 427.

6a. Addis, T., The effect of intravenous injections of fresh human serum and of phosphated blood, on the coagulation time of the blood in hereditary hemophilia. Proc. Soc. Exper. Biol. and Med., 1916-17, 14, 19.
7. Minot, G. R., and Lee, R. I., The blood platelets in hemophilia. Arch. Int. Med., 1916, 18, 474.

8. Hurwitz, S. H., and Lucas, W. P., A study of the blood in hemophilia. Arch. Int. Med., 1916, 17, 543.

9. Christie, R. V., Davies, H. W., and Stewart, C. P., Studies in blood coagulation and hemophilia. II. Observations on haemic functions in haemophilia. Quart. J. Med., 1927, 20, 481.

10. Lee, R. I., and Vincent, B., The coagulation of normal human blood. An experimental study. Arch. Int. Med., 1914, 13, 398.

11. Nygaard, K. K., Coagulability of blood plasma. Remarks on the technic of its determination. Proc. Staff Meet., Mayo Clin., 1934, 9, 151.

12. Cramer, W., and Pringle, $H$., On the coagulation of blood. Quart. J. Exper. Physiol., 1913, 6, 1.

13. Goddard, C. H., The effect of filtration through a Berkefeld filter upon the coagulability of oxalated plasma. Am. J. Physiol., 1914, 35, 333.

14. Fonio, A., Die Unterkühlungs-Zentrifugiermethode. Ztschr. f. klin. Med., 1932, 119, 687.

15. Wöhlisch, E., Untersuchungen zum Hämophilieproblem, insbesondere zur Thrombocytenfrage. Ztschr. f. d. ges. exper. Med., 1923, 36, 3.

16. Howell, W. H., and Cekada, E. B., The cause of the delayed clotting of hemophilic blood. Am. J. Physiol., 1926, 78, 500.

16a. Howell, W. H.: The condition of the blood in hemophilia, thrombosis, and purpura. Arch. Int. Med., 1914, 13, 76.

17. Birch, C. L., Hemophilia. J. A. M. A., 1932, 99, 1566.

18. Eagles, H., Studies on blood coagulation. IV. The nature of the clotting deficiency in hemophilia. J. Gen. Physiol., 1935, 18, 813.

19. Feissly, R., and Fried, A., Die Blutplättchen des Hämophilen Blutes. Klin. Wchnschr., 1924, 3, 831.

20. Klinger, R., Studien über Hämophilie. Ztschr. f. klin. Med., 1917, 85, 335.

21. Govaerts, P., and Gratia, A., Contribution à l'étude de l'hémophilie. Rev. belge sc. méd., 1931, 3, 689. 